\title{
Afetividade e construção do conhecimento: a produção textual como portadora de conteúdo
}

Anna Selmira Jardim da Silva

Mestre em Educação pela UFRGS

\section{Resumo}

Este trabalho aborda a Afetividade através da produção textual de alunos do Ensino Fundamental e Médio e busca evidenciar como a produção textual, enquanto prática pedagógica representa um poderoso e eficiente instrumento de aproximação entre o sujeito cognitivo e o objeto de conhecimento. A relação sujeito/objeto é dinamizada por representações simbólicas e do mundo, promotoras da aprendizagem da língua, mediante a linguagem escrita e o processo de subjetivação, a partir da tomada de consciência e da reflexão dos conteúdos veiculados pelo texto. Evidencia-se a importância da afetividade no processo de aprendizagem e na construção da subjetividade e da consciência crítica do sujeito.

Palavras-chave: Construção do Conhecimento; afetividade; produção textual.

\section{Resumen}

Este trabajo trata a la afectividad en el interior de los discursos pronunciados en la producción textual de los estudiantes de Primaria y Secundaria, y busca evidenciar cómo la producción textual, desde la práctica pedagógica representa una poderosa y eficiente herramienta de aproximación entre sujeto cognitivo y obyecto del conocimiento. Se lleva a cabo una investigación sobre la importancia de la afectividad en el proceso de construcción de conocimientos. Muestra cómo el afecto agiliza el proceso de aprendizaje de la lengua escrita, teniendo la producción textual como una herramienta de investigación de representaciones simbólicas que los estudiantes / autores tienen de su entorno social.

Palabras-clave: Construcción del Conocimiento; afectividad; Producción Textual. 


\section{Introdução}

bordar a aprendizagem sob o ponto de vista da afetividade
pressupõe o entendimento da necessidade da formação de um
sujeito pleno, que seja uma simbiose entre razão e emoção.

A aprendizagem vista como parte do processo de desenvolvimento mental do ser humano, não pode prescindir dos componentes energéticos das ações que permitem a formação desse ser integral. Neste contexto, a linguagem escrita, entendida como ação de segundo grau, ou seja, uma ação que se debruça sobre uma ação anterior; proporciona um espaço de trocas e reflexões sobre o cotidiano, tanto do professor, quanto do aluno e têm suas implicações no processo de construção de conhecimento.

Uma das limitações apresentadas pela temática é a consciência do quanto damos valor ao aspecto racional da aprendizagem, da construção do conhecimento, esquecendo-nos na maioria das vezes de que somos sempre mobilizados, em nossas ações, pelos nossos interesses, pela necessidade e pela vontade de conhecer algo e de nos projetarmos como sujeito; somos movidos pelos nossos desejos (FURTH, 1995).

Entendemos tanto a linguagem como a afetividade como portadoras de funções adaptativas, uma vez que pela linguagem, em qualquer de suas modalidades, podemos expressar, o que pensamos e o que sentimos. Ao nos expressarmos através da linguagem, colocamo-nos em relação com o outro, fazendo-o conhecedor daquilo que conhecemos e constituindo-nos mutuamente como sujeitos através da interação. Assim, o texto poderá ser visto como um dinamizador da aprendizagem da linguagem escrita.

O tema gerador deste texto é a Afetividade, e o universo empírico é constituído por textos produzidos por alunos de Ensino Fundamental e de Ensino Médio. São textos descritivos, narrativos e dissertativos, que, apesar de apresentarem alguns problemas de estrutura, de ortografia, sintaxe, etc. trazem consistentes exemplos do modo como os alunos 
estruturam e representam o universo em que estão inseridos, como veem e como pensam o mundo e a sociedade da qual fazem parte; como sentem os problemas dessa sociedade.

Nesses textos vislumbram-se tanto aspectos cognitivos, quanto afetivos dos sujeitos, por esse motivo considero esse material como importante indicativo da relação entre cognição e afetividade.

É nesse aspecto que afirmo que através de seus textos, os alunos expressam representações sociais, ou seja, apresentam um conhecimento cotidiano que não pode ser ignorado, pois além de integrarem a personalidade (do sujeito) em formação, também representam as percepções, as reações e as tomadas de consciência, e de posicionamento do sujeito diante das coisas que o afetam.

Considero que a produção textual constitui-se como espaço de enunciação, de criação e de interlocução, pois através do texto, o sujeito autor enuncia o seu mundo interior, cria a partir do processo de assimilação do mundo circundante, elege um interlocutor (ainda que virtual) e através dessa criação, realiza as acomodações necessárias ao conhecimento do objeto, neste caso a estrutura formal da língua.

A questão da singularidade da enunciação evidencia-se pela forma de expressão de um conjunto de ações interiorizadas, formadoras de uma totalidade representada pelo texto.

O texto passa então a ser, além de uma totalidade linguística, um importante espaço de tomada de consciência da realidade circundante do sujeito enunciador. Espaço este no qual realiza operações a partir de sua ação sobre o mundo ou de sua mera observação, através da reflexão sobre seu modo de estar nesse mundo. Isso porque o texto enquanto ação interiorizada leva o sujeito a uma reflexão e consequente tomada de consciência.

Na produção textual, o sujeito em seu ato de escrever, está na verdade realizando uma seleção de eventos, uma classificação, uma valoração desses 
eventos e uma inserção dos mesmos numa totalidade que é o texto. E esse processo está carregado de afetividade. Isso constitui uma operação, ou seja, é uma coordenação de ações que leva à constituição de uma rede de significações.

Os textos analisados foram coletados em atividades normais de produção textual, não constituindo instrumento específico de caráter experimental, e o critério para a seleção dos mesmos teve por base os aspectos cognitivos e afetivos identificáveis nesses textos.

Os objetivos do trabalho com produção textual em sala de aula eram, por um lado, a construção de conhecimentos linguísticos e textuais, por outro a observação de estruturas cognitivas do sujeito, sua visão de mundo, suas colocações de pontos de vista, suas manifestações afetivas no que diz respeito aos valores morais tais como solidariedade, justiça, amizade etc. Ou seja, um trabalho que nos permitisse, além do acompanhamento das aprendizagens do sujeito em relação ao ensino da língua, também oportunizasse ao sujeito um espaço de expressão e reflexão sobre sua realidade mais próxima, levando-o a constituir-se como um sujeito ativo, que gradativamente adquire condições de participação no mundo, enquanto sujeito sócio-histórico.

Esses objetivos levam-nos a duas instâncias particulares: de um lado a questão mais pedagógica, que visa a vencer os problemas cognitivos e afetivos em sala de aula. Busca-se, através da afetividade do sujeito com o objeto de estudo (neste caso a Língua Portuguesa), levá-lo a superar os obstáculos apresentados pelo próprio ambiente (sala de aula/escola), nos casos de turbulência gerada por indisciplina, e de superação de sua realidade social, nos casos de turbulência gerada por violência, criminalidade, “drogadição” e outros problemas sociais, ou ainda nos casos de inclusão.

O interesse dos estudos sobre a afetividade para a Epistemologia Genética (abordagem teórica deste trabalho) está relacionado à possibilidade de investigação sobre a lógica do sujeito, a evolução de seu pensamento, de seu desenvolvimento mental, através de suas construções sociais, 
principalmente através da correlação entre os estágios cognitivos e afetivos.

Tal investigação, partindo da categoria sujeito, descreve-o como um ser situado em um tempo e um espaço definido. Um ser histórico e social com direitos e deveres, que tem vontades e necessidades, que tem simpatias e antipatias. Um ser que se relaciona com outros seres. Enfim, um ser que age e cuja ação tem intencionalidade, cuja ação é motivada por interesse e necessidade Um ser cuja força que empreende para a realização de determinado objetivo está em relação com o aspecto afetivo de sua conduta, fazendo dessa ação uma ação significativa e transformando o conhecimento em desejo e o desejo em conhecimento.

\section{Afetividade e linguagem}

Para Piaget (1983b, p.226) o desenvolvimento intelectual constitui-se de um aspecto cognitivo e de um aspecto afetivo. No âmbito cognitivo, temos o processo de desenvolvimento e a aprendizagem a partir da formação de esquemas, que por sua vez compõe as estruturas cognitivas. Ao verificarmos o nível de conhecimento e o tipo de raciocínio do sujeito, estamos na esfera cognitiva. Já o que se refere às emoções, sentimentos, vontade, interesses, necessidades, moralidade, pertence à esfera afetiva, ou seja, compõe a energética das condutas cognitivas ou comportamentos intelectuais.

Damásio (1996, p.62) afirma que estudos em seu laboratório mostraram que a emoção integra os processos de raciocínio e decisão. Diz que “as emoções não são um luxo indispensável. As emoções são adaptações singulares que integram o mecanismo com o qual os organismos regulam sua sobrevivência” (Damásio, 1996, p.62).

Para termos conhecimento dos sentimentos expressos por determinada emoção, passamos por um processo de tomada de consciência como o que ocorre no processo de conhecimento de qualquer outro objeto. O indivíduo que expressa determinada emoção, para identificá-la com o sentimento que a provocou, realiza uma coordenação das ações circunstanciais que 
engendraram essas emoções. “[...] emoção como indica a palavra, diz respeito a movimento, a comportamento exteriorizado, a certas orquestrações de reações a uma causa dada, em um meio determinado.” (Damásio, 2000, p.98).

Piaget (1983b) define afetividade como energética das estruturas cognitivas, ou seja, o aspecto responsável por tudo que nos mobiliza para a realização de nossas ações, podendo ser responsável, inclusive, pela aceleração ou pelo retardamento da construção dessas estruturas. Aceleração conforme os casos de interesse e necessidade do sujeito, dirigindo-se desta forma, para os conteúdos, ou de retardamento nos casos em que a situação afetiva é obstáculo para o desenvolvimento intelectual do sujeito.

Situa a afetividade desde o período sensório-motor, iniciando-se com as emoções primárias (sentimentos de medo, sensações agradáveis ou desagradáveis etc.). Conforme ele, os aspectos afetivos e cognitivos das condutas são inseparáveis. Desta forma, ao tratarmos sobre afetividade como energética não temos como evitar direta ou indiretamente o trato com as emoções, uma vez que participam de nossas vidas em uma instância biológica.

É de nosso conhecimento, no entanto, que para que se dê a aprendizagem, é necessária a construção prévia da estrutura de assimilação, ou o sujeito não dará conta do conteúdo a ser assimilado (Becker, 2003).

Assim, abordar a linguagem sob o ponto de vista da afetividade pressupõe o entendimento da relação entre a linguagem e as operações intelectuais, conforme os estudos de Piaget (1983b, p.226), nos quais afirma que a linguagem permanece como condição necessária do acabamento das estruturas lógicas, pelo menos ao nível das estruturas proposicionais, não sendo, no entanto, condição suficiente para a formação das estruturas lógico-matemáticas.

Com isso faz-se necessário que façamos um breve apanhado das relações entre desenvolvimento cognitivo e afetivo, no período sensóriomotor, antes do aparecimento da linguagem, quando haverá, conforme os 
estudos de Piaget, uma profunda modificação das condutas no aspecto afetivo e cognitivo.

Piaget (1964, P.267-268) apresenta três estágios bem definidos do desenvolvimento anterior ao aparecimento da função simbólica e da linguagem. O primeiro corresponde aos impulsos instintivos elementares, ligados à alimentação e as emoções primárias como os primeiros medos. Um segundo estágio ligado às percepções e hábitos, bem como os sentimentos elementares ou afetos perceptivos ligados à atividade própria, tais como sensações agradáveis ou desagradáveis, o prazer e a dor e os primeiros sentimentos de sucesso e fracasso. Neste estágio vigora uma espécie de egocentrismo, em função de o bebê não ter ainda consciência de seu $e u$, nem das relações mantidas com outras pessoas, pois não se formou ainda o esquema do objeto permanente, que aparece mais ou menos ao final do primeiro ano. O terceiro estágio aparece com a formação do esquema do objeto permanente e é caracterizado pela objetivação dos sentimentos e pela projeção sobre outras atividades diferenciadas do próprio sujeito. Aparecem os sentimentos de alegria e tristeza ligados ao sucesso e ao fracasso dos atos intencionais. Nesse período aparecem também os esforços e interesses ou fadigas e desinteresses, sendo todos eles estados afetivos ligados às ações próprias.

A partir do aparecimento da função semiótica as condutas do sujeito sofrem mudanças profundas, tanto em seu aspecto afetivo quanto intelectual. A principal dessas mudanças é o aparecimento da linguagem, que proporcionará ao sujeito a possibilidade de reconstituição de suas ações, sob a forma narrativa, ou a antecipação de suas ações futuras por meio da representação verbal.

Damásio (2000, p.144-145), ao estabelecer uma relação entre linguagem e consciência, define a linguagem como "a tradução de uma outra coisa, uma conversão de imagens não linguísticas que representam entidades, eventos, relações e inferências”.

Damásio atribui à linguagem a capacidade de traduzir precisamente 
pensamentos em palavras e sentenças e vice-versa, a aptidão de classificar conhecimentos de maneira rápida e econômica através da palavra e ainda a capacidade de expressar construções imaginárias ou abstrações através da palavra simples e eficaz.

Retomamos aqui o questionamento sobre a relação entre o aparecimento da linguagem e da função semiótica, ou capacidade de representação, estágio em que a criança passa a representar objetos e eventos ausentes através da linguagem. Ou seja, retomamos o questionamento sobre a relação que se estabelece entre linguagem, pensamento e as operações lógicas.

Uma vez revisada a questão da afetividade até o aparecimento da função semiótica, cabe-nos ensaiar as possíveis contribuições das teorias de aprendizagem aos estudos da linguagem. Segundo Piaget, a linguagem comporta a lógica inerente ao sistema da língua, ou seja, as principais estruturas operatórias estão, sim, inscritas na linguagem, seja sob uma forma sintática, seja semântica, primeiramente no que se referem às operações concretas, que se dirigem aos objetos, no tocante às classes, relações e números, até atingir as operações proposicionais, referindo-se às possibilidades combinatórias.

É preciso, então, entender a linguagem como já elaborada socialmente e dotada de instrumentos cognitivos a serviço do pensamento.

Bakthin (1992, p.112) nos diz que "O conteúdo a exprimir e sua objetivação externa são criados [...] a partir de um único e mesmo material, pois não existe atividade mental sem expressão semiótica”. Diz ainda que: “o centro organizador e formador não se situa no interior, mas no exterior. Não é a atividade mental que organiza a expressão, mas ao contrário é a expressão que organiza a atividade mental, que a modela e determina sua orientação”.

Essa passagem, apesar de sua visão empirista, até certo ponto, sintoniza com a teoria piagetiana. A diferença fundamental é que para Piaget, ambos (sujeito e objeto) organizam-se mutuamente, de forma 
relacional, ou seja, para Piaget, o conhecimento se dá num determinado ponto chamado periferia, e que para cada movimento em relação ao objeto, corresponde um movimento em relação ao sujeito, conforme figura representativa do processo de tomada de consciência apresentada a seguir.

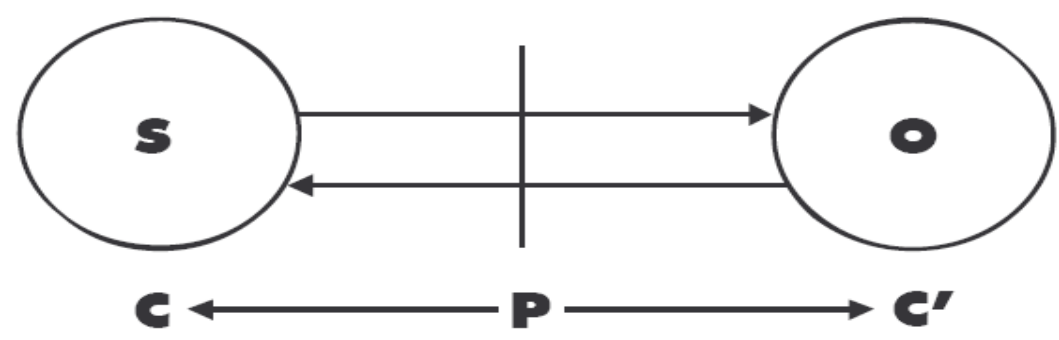

Figura 1: Diagrama da Tomada de consciência Fonte: Piaget 1977

Também para Piaget o conhecimento não se dá como acontecimento interior, mas sim a partir dos movimentos do sujeito em direção aos objetos e das simultâneas transformações que o objeto realiza no sujeito, num processo dinâmico de assimilações e acomodações. Desta forma, a ênfase na construção do conhecimento está nas ações do sujeito.

Segundo Bakthin (1992), a expressão exerce um efeito reversivo sobre a atividade mental, ou seja, há uma interação do sujeito com o meio que estrutura a atividade mental. O sujeito ao se apropriar dos conteúdos do meio e ao expressá-los forma estruturas que organizam sua vida interior.

Em nosso caso, ao tomarmos o texto como espaço de comunicação e de expressão das ações interiorizadas do sujeito, ou seja, como espaço de convergência da atividade mental, entendida como ação interiorizada, e da expressão semiótica, das representações que o sujeito realiza, reconstituímos simultaneamente o mundo interno e o mundo externo do sujeito.

A linguagem, para Piaget, tem como base a capacidade de diferenciar significantes de significados, como capacidade de representação. Está ligada à função simbólica.

Isso nos permite pensar, em relação ao texto, que justo por ser a expressão organizadora da atividade mental é que podemos dizer que existe 
uma relação estrita entre a organização mental, entre a estrutura cognitiva e a organização textual, que veiculará os diferentes conteúdos representados pelo sujeito.

É preciso que vejamos o texto (produção textual) como forma de expressão de uma atividade mental, como exteriorização de uma ação interiorizada. Não apenas como forma de determinação do sujeito, mas também em sua instância comunicativa.

Benveniste (1995, p.285) afirma que a linguagem está na natureza do homem, que a linguagem não foi fabricada pelo homem. O linguista considera que:
"Todos os caracteres da linguagem, a sua natureza imaterial, o seu funcionamento simbólico, a sua organização articulada, o fato de que tem um conteúdo, já são suficientes para tornar suspeita essa assimilação [da linguagem] a um instrumento que tende a dissociar do homem a propriedade da linguagem”.

Benveniste afirma que é a linguagem que habilita a palavra à comunicação e que "É na linguagem e pela linguagem que o homem se constitui como sujeito”.

Essa construção de subjetividade que se dá na interação e tem por base o conceito de ego, opondo um eu a um tu que se constituem mutuamente, remete-nos a Piaget quando diz que o conhecimento se dá na e pela interação de um sujeito e um objeto. De um sujeito que a cada movimento em direção ao objeto, transforma esse objeto ao mesmo tempo em que transforma a si mesmo.

O linguista suíço Ferdinand de Saussure (1997, p.22) faz uma distinção entre língua, enquanto sistema de signos e fala, uso que o indivíduo faz desse sistema de signos. Diz que a língua é um sistema de signos em oposição, no qual um signo é o que o outro não é. Desta forma ao fazer uso da língua através da linguagem oral ou escrita o indivíduo está na realidade operando um sistema de signos articulados que se ligam segundo determinadas convenções. A apropriação desse sistema começa muito cedo, por volta dos dois anos o sujeito já tem esse sistema de signos em 
funcionamento através da linguagem e do aparecimento da função simbólica.

Acontece que a linguagem faz parte de um processo evolutivo, a aprendizagem da língua, enquanto estrutura se dá a partir da inclusão do sujeito na educação formal (escolar) e, neste aspecto, depende do processo de ensino-aprendizagem, não devendo ser utilizado como mecanismo de exclusão. E se essa aprendizagem depende do ensino, depende também das teorias que embasam o trabalho do professor, da visão epistemológica que este possui e que norteiam a sua prática.

Na verdade a forma como o professor ensina não é o principal para que haja aprendizagem, apesar de não podermos prescindir da ação do mesmo. A aprendizagem se dá ou não à revelia da teoria usada, porque na verdade o que importa para que haja aprendizagem é a interação do sujeito com o objeto de aprendizagem. Importa também a afetividade subjacente ao trabalho docente e ao esforço do sujeito da aprendizagem.

Quando falamos em afetividade, falamos de valores, de moralidade, de vontade, de motivação. Quando falamos em afetividade referimo-nos a questão dos valores envolvidos, da vontade, da energética que mobiliza o sujeito para determinada ação.

Gosto de uma reflexão do arquiteto Oscar Niemeyer, que muito bem exemplifica o que é a energética de uma ação. Nessa reflexão ele diz:

"não é o ângulo reto que me atrai, nem a linha reta, dura, inflexível, criada pelo homem. O que me atrai é a curva livre e sensual, a curva que encontro nas montanhas do meu país, no curso sinuoso dos rios, nas ondas do mar, no corpo da mulher preferida. De curvas é feito todo o universo, o universo curvo de Einstein".

Assim é o sujeito que age. Subjacente a sua ação há algo que o mobiliza, que o impulsiona para a ação. É o que Piaget chamou energética da ação (Piaget, 1972, p.226). Desta forma, percebemos o quanto há de afetividade, de energética em nosso trabalho intelectual, cognitivo.

Conforme Piaget (1964, P.267-268) existe um paralelismo constante 
entre a vida afetiva e a intelectual, que seguirá no curso do desenvolvimento da infância à adolescência; arrisco dizer que até a vida adulta.

Ao retomarmos a questão do paralelismo entre afetividade - no que diz respeito à motivação, vontade, moralidade - e operações intelectuais, e fazendo um comparativo com a linguagem, por exemplo, no estudo das relações oracionais com ou sem uso de conjunções; subjacente a esse tipo de conteúdo temos a formação de juízos concomitante ao estabelecimento da combinatória.

Esse conteúdo está relacionado também à forma de interação do sujeito com o meio, pois se o adolescente não está habituado a coordenar seus pontos de vista com o de seus pares, torna-se difícil o entendimento da transposição dessas estruturas enquanto conteúdo (orações coordenadas e subordinadas). Basta observarmos o difícil entendimento que têm do significado veiculado pelos nexos frasais (conjunções). Se observarmos a produção escrita de crianças e adolescente de acordo com os estágios operatórios, segundo Piaget, poderemos também observar uma evolução na construção sintática. Primeiro com a produção de períodos simples, de uma só oração, que expressam percepções individuais, evoluindo para a composição do período composto, num primeiro momento através da coordenação de ideias (orações coordenadas) e posteriormente para a linguagem mais elaborada, já passível de subordinação, resultado da combinatória de ideias que se reflete na construção sintática.

A linguagem, enquanto estrutura é, pois, um instrumento de comunicação de nossos pensamentos, de nossos sentimentos, de nossas ideias. O estudo da estrutura da língua nos torna mais eficiente em nossas produções, mas é pela linguagem, enquanto sistema de expressão, que nos constituímos como sujeito que age; como sujeito que ao agir constrói significados, realiza representações. Desta forma o trabalho com produção textual, o texto relacionado às estruturas lógico-matemáticas, pode ser visto como uma totalidade operatória dotada de reversibilidade, tanto em seu aspecto linguístico, quanto formal, e é dotado de afetividade, uma vez que 
afetividade e cognição são dois aspectos inseparáveis. O sujeito ao agir sobre o mundo constrói representações que veicula através do texto, num processo continuo de assimilações e acomodações que promovem a adaptação do sujeito ao meio, a partir da tomada de consciência de suas ações, tornando-o um sujeito pleno. Um sujeito linguístico, cognitivo, psicológico. Um cidadão consciente que age sobre o mundo e com sua ação transforma-o.

\section{Considerações finais}

O trabalho pedagógico com produção textual, enquanto prática relacionada à Epistemologia Genética tem sua legitimidade na medida em que a partir da leitura de textos diversos, da escrita e leitura de seu próprio texto, o sujeito-autor realiza um processo de abstração com base nas ações veiculadas pelo texto.

Esse processo leva-o a uma tomada de consciência e consequente aprendizagem dos conteúdos cognitivos e afetivos, sejam eles a aprendizagem da língua, através do uso da linguagem oral e escrita, ou as questões morais e éticas que compõem a estrutura afetiva do sujeito.

A partir do momento em que o sujeito-autor objetiva o seu meio e passa a refletir sobre as relações interpessoais realizadas nesse meio, entramos no campo da moralidade. Na medida em que o aluno é capaz de desenvolver uma narrativa coerente, ainda que metafórica, estabelece uma relação dialética e dialógica que evidencia sua capacidade de representação do seu mundo circundante, sua interação social na busca do bem-comum, que o situa no campo da ética.

Algumas dessas narrativas em questão apresentam uma preocupação implícita com os problemas vividos pela comunidade e com o bem-estar da mesma. Esses textos objetivam e refletem os acontecimentos, as situações conflituosas e eventos positivos ou negativos do meio narrado. Por isso, alguns fatos narrados, por pertencerem ao âmbito da criminalidade, por vezes vêm camuflados por metáforas e alegorias, em outras apresentam a 
ingenuidade de um sujeito que vivencia os fatos como quem assiste a um filme sobre o qual não podendo agir nada pode alterar de sua realidade.

Ao elaborar seu texto, o sujeito para muito além do simples plano descritivo, ao registrar suas impressões através da descrição sensorial do ambiente observado e da organização desse conteúdo em uma estrutura formal, evidencia suas condutas enquanto observador, construindo uma rede de representações e significações no interior da qual ele próprio se constitui como sujeito. O resultado é uma simetria entre o observador e o ambiente, evidenciando um intenso processo de assimilação, na medida em que registra os objetos; e de acomodação, na medida em que transforma seus esquemas para melhor assimilar esses conteúdos, realizando-se um processo de adaptação, na medida em que se assume como sujeito em interação com o espaço descrito.

Ao escrever seu texto, ao descrever seu ambiente, ao apresentar suas opiniões, suas argumentações, seus juízos de valor sobre determinada situação; o aluno não só diz o seu texto, revela o seu mundo, como também e, principalmente, revela seu mundo interior. Revela sua determinação enquanto sujeito (PÊUCHEUX, 1995).

Saussure (1979, p.22) deu à fala um status de ato individual de vontade e inteligência e Benveniste (1995) considerou a enunciação como processo de apropriação da língua enquanto realização individual. Essa evocação da individualidade, vista no âmbito da produção textual enquanto processo de subjetivação, no qual também "este sujeito é livre e orienta seu discurso segundo seus interesses, mobilizando a língua para dizer o que quer dizer” (GERALDI, 1996 p. 13), reafirma a construção de um sujeito linguístico e psicológico.

Esse sujeito, através da enunciação emprega a língua (estrutura) para expressar sua relação, sua interação com o mundo. Isso coloca o texto tanto numa instância enunciativa quanto discursiva, uma vez que o sujeito ao assumir-se como um "eu” (locutor), que se dirige a um "tu” (leitor), ao enunciar o que "quer” dizer, assume uma formação discursiva que o situa 
enquanto sujeito, num tempo e num espaço próprio, ou seja, situa-o como sujeito sócio-histórico.

As observações que fiz no cotidiano de minha prática educacional serviram de motivação para situar a afetividade como temática desta pesquisa. Era-me instigante observar o quanto havia de intelectualidade nas condutas mais simples do dia-a-dia dos meus alunos. A forma como se efetivavam as relações interpessoais na sala de aula, as atitudes de coleguismo, as dissensões, as disputas pessoais entre colegas, as necessidades de superação de suas dúvidas, os aspectos afetivos positivos e negativos nas formas de comunicação entre os alunos, tudo apontava para uma instância afetiva e emocional.

Tomei consciência, tanto teórica quanto empiricamente, que a afetividade por ser a energética das estruturas cognitivas, jamais se separa destas. E era o que eu podia observar no contexto de minha própria sala de aula. Observei que os alunos o tempo todo realizavam operações que se evidenciavam tão afetivas quanto cognitivas: a emissão de juízos de valor em relação à conduta dos colegas e por vezes de sua própria conduta ao expressar “o que ele fez é errado”, ou “eu sei que agi errado”.

É nesse contexto das relações entre afetividade e cognição que podemos dizer que as emoções têm uma função adaptativa (Damásio, 2000). É ainda nesse contexto que podemos relacionar as emoções às nossas formas e possibilidades de dizer o que sentimos e o que pensamos, ou seja, podemos relacionar afetividade e linguagem e, consequentemente, afetividade e produção textual, linguagem escrita, enquanto forma de expressão de nossas ideias e de nossos sentimentos.

A afetividade está relacionada a tudo que nos mobiliza em nossas ações, no que diz respeito ao que fazemos e ao que pensamos; ao que falamos, ao modo de encarar as relações. Está relacionada também ao afeto, à intencionalidade, à ética, à moralidade. Assim que, a vida escolar e o cotidiano externo à escola não podem ser totalmente separados, pois formam um todo coeso e coerente é de suma importância no processo 
de construção de conhecimento.

Por isso busquei entender que representações de mundo os alunos apresentavam em seus textos, pois, como muitas vezes encontrei meus alunos preocupados com fatos externos à escola, que os haviam afetado emocionalmente, minha hipótese era que as representações de mundo e as vivências sociais podem gerar desequilíbrios que influenciam na aprendizagem.

É nesse aspecto que dizemos que abordar a aprendizagem sob o ponto de vista da afetividade pressupõe o entendimento da necessidade da formação de um sujeito pleno, que saiba coordenar razão e emoção; que construa sua razão, pois a aprendizagem, vista como parte do processo de desenvolvimento mental do ser humano depende dos componentes energéticos das ações, indispensáveis à formação desse ser humano integral.

A aprendizagem depende de inúmeros fatores, entre eles o comprometimento do próprio aluno e um ambiente propício à construção do conhecimento, tendo como pressupostos básicos a cooperação, a disciplina e a autonomia. Abordar a afetividade a partir da produção textual de meus alunos busca entender e colocar em pauta de discussão alguns dos principais problemas da educação, tais como a evasão, a reprovação e a (in)disciplina. Busca também inserir o texto como um dinamizador da aprendizagem da língua, partindo do pressuposto que os alunos, ao trabalharem a produção textual, além de intensificarem sua aproximação com os mecanismos da língua e a aprendizagem de sua estrutura, também encontram um espaço de reflexão que oportuniza seu desenvolvimento cognitivo.

É sob esse ponto de vista que digo que ao tomarmos o texto como espaço de comunicação e de expressão das ações interiorizadas do sujeito, ou seja, como espaço de convergência da atividade mental, entendida como ação interiorizada, e da expressão semiótica - das representações que o sujeito realiza - reconstituímos simultaneamente o mundo interno e o mundo externo do sujeito. 
É ainda sob esse ponto de vista que a produção textual constitui-se como espaço de enunciação, de criação e de interlocução. De criação, porque é nesse espaço que o aluno pode partir do ponto em que está e desenvolver estruturas cognitivas mais elaboradas, utilizando-se de conteúdos conhecidos por ele, e conhecidos porque vivenciados, sentidos, carregados de afetividade, apresentando novidades que apontam para seu crescimento intelectual.

Esse aspecto da produção textual tornou-se evidente, pois através do texto, os sujeitos (autores) enunciavam o seu mundo interior, num intenso processo de assimilação do mundo circundante. E essa assimilação mental é atravessada constantemente pelas vivências afetivas.

O texto evidenciou-se uma totalidade linguística, que ao mesmo tempo em que se apresentou como instrumento de sondagem, também se revelou um importante espaço de tomada de consciência da realidade circundante do sujeito enunciador e, correlativamente, de tomada de consciência de sua própria subjetividade. Esse espaço, representado pelo texto, é o espaço no qual o sujeito realiza operações a partir de sua ação sobre o mundo, através da reflexão sobre seu modo de estar nesse mundo.

Em relação às representações de mundo encontrei nos textos exemplos bastante representativos de situações que ao mesmo tempo em que causam desequilíbrios, também se revelam condições necessárias à reflexão e à tomada de consciência da realidade dos referidos sujeitos, de forma que o universo escolar e a realidade externa na qual o aluno está inserido já não podem ser separadas, e um desequilibra o outro, ou seja, situações externas têm influência no universo escolar, e este pode influenciar e mesmo transformar a realidade externa. 


\section{Referências Bibliográficas}

BAKHTIN, Mikahil. Marxismo e Filosofia da Linguagem. São Paulo: Ed. Hucitec, 1992.

BECKER, Fernando. A origem do conhecimento e a aprendizagem escolar. Porto Alegre: Artmed, 2003.

BENVENISTE, Émile. Problemas de Linguistica Geral I. Campinas, SP: Pontes, 1995.

DAMÁSIO, António Rosa. O erro de Descartes: emoção, razãa e o cérebro bumano. São Paulo, Companhia das Letras, 1996.

DAMÁSIO, António Rosa. O Mistério da consciência: do corpo e das emoções ao conhecimento de si. São Paulo, Companhia das Letras, 2000.

FURTH, Hans G. Conhecimento como desejo: um ensaio sobre Freud e Piaget. Porto Alegre: Artes Médicas, 1995.

GERALDI, João Wanderley. Linguagem e Ensino: exercícios de militância e divulgação. Campinas: Mercado de Letras; ALB, 1996.

PÊUCHEUX, Michael. Semântica e Discurso: uma crítica à afirmação do óbvio. Campinas: Editora da UNICAMP, 1995.

PIAGET, Jean. A construção do real na criança. In: Os Pensadores. São Paulo: Abril Cultural, 1983.

- A formação do símbolo na criança: imitação, jogo e sonbo; imagem e representação. Rio de Janeiro: Zahar Ed., 1964.

Cultural, 1983b.

Problemas de Psicologia Genética. In: Os Pensadores. São Paulo: Abril A tomada de consciência. São Paulo: EDUSP-Melhoramentos, 1977. 